\title{
Sternal retractor for improved vision during bilateral internal mammary artery implantation
}

\author{
CEDRIC DEAL AND IAN MONK
}

\section{From the Unit of Clinical Investigation and the Cardio-thoracic Unit, Royal North Shore Hospital, Sydney}

The importance of the principle of implantation of the internal mammary artery into the myocardium, as described by Vineberg (1946), is now well established. The advantages of implanting both internal mammary arteries into the myocardium have been described by Favaloro, Effler, Groves, Fergusson, and Lozada (1968), and this may be the operation of choice when this method is used. The median sternotomy necessitated by such a double implant makes the dissection of the pedicles containing the internal mammary vessels a little tedious by the usual retraction method. Even the fixed retractors described by Favaloro (1967) from the Cleveland Clinic employ a vertical

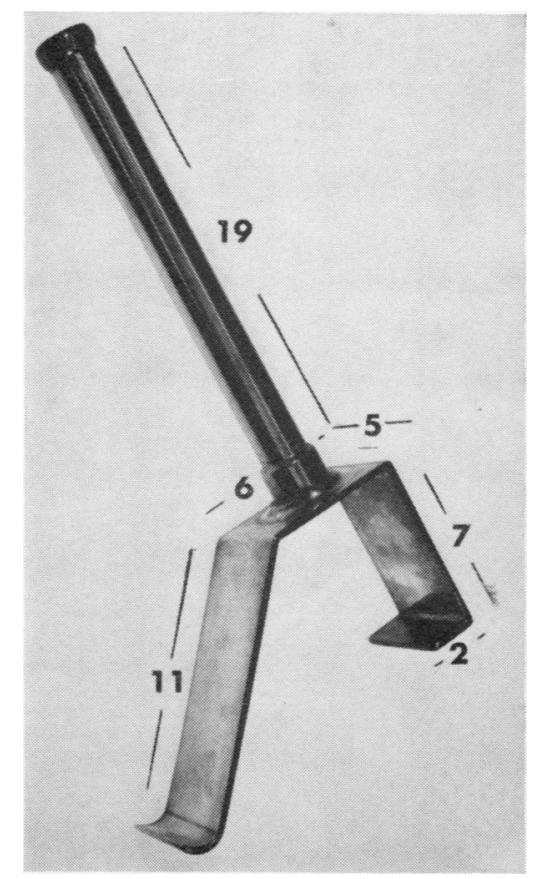

FIG. 1. Sternal retractor showing dimensions in centimetres. lift which still entails the operator working under a ledge.

We have designed a retractor (Fig. 1) which takes advantage of the mobility of the costochondral joints and posterior costo-vertebral joints to fold the sternum outwards. This retractor employs a lever system in which the foot is hitched underneath the sternal edge and the tail of the retractor acts as a fulcrum on the chest wall. The handle of the retractor is used as a lever. The amount of force necessary to provide access is minimal. A sponge can be placed beneath the tail of the retractor in order to spread the pressure area, although this bearing area has been made purposely large. The retractor has bsen used suocessfully in the last six operations and the vision afforded has been excellent (Fig. 2).

The retractor is simply made, the present model having been made in the hospital workshop from a single piece of brass plate and a piece of brass tubing, chromed after construction. The dimen-

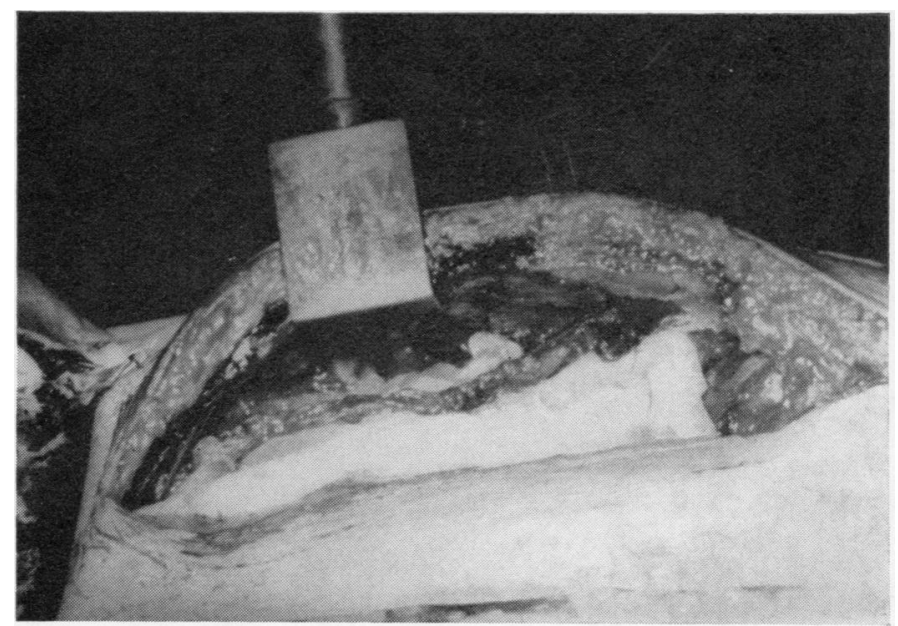

FIG. 2. Retractor in use demonstrating the exposure obtained. 
sions are shown in Figure 1. Two features are important: the depth of the foot should not be excessive as it may encroach upon the internal mammary vessels, and the tail should have an adequate bearing area.

We wish to thank Mr. R. Sherwood for his help in constructing the retractor.

\section{REFERENCES}

Favaloro, R. G. (1967). Unilateral self-retaining retractor for use in internal mammary artery dissection. $J$. thorac. cardiovasc. Surg., internal 864 .

- Effler, D. B., Groves, L. K., Fergusson, D. J. G., and Lozada, J. S. (1968). Double internal mammary artery-myocardial implantation. Clinical evaluation of results in 150 patients. Circulation, 37, 549.

Vineberg, A. M. (1946). Development of an anastomosis between the coronary vessels and a transplanted internal mammary artery. Canad. med. Ass. J., 55, 117. 